perfusion. They have risen to normal levels over the next 12 hours and their deficiency has not been a cause of bleeding.

\section{Wound Infection}

The precautions governing the sterility of the heartlung machine, the detection of likely staphylococcal carriers, and the standard antibacterial cover given against infection appeared to have been adequate. There were four cases of wound infection-three major and one minor. The pre-operative nasal swab revealed no growth in three and a penicillin-sensitive staphylococcus in the remaining case. All four were cured conservatively.

\section{Non-infective Pulmonary Changes Interfering with Respiration}

These have been a problem in all cases. Tachypnoea was reported specifically in 19 . The post-operative temperature has varied from 100 to $104^{\circ} \mathrm{F}$. (37.8 to $40^{\circ} \mathrm{C}$.), reaching a peak on the third day and subsiding over the next few days. Of 12 patients with extensive pulmonary collapse, six died. Post-operative $x$-ray films have revealed diffuse infiltrations in lung parenchyma, most pronounced at the site of internal impingement of the chest drainage tubes. This picture differs from the classical segmental distribution of post-operative collapse. At necropsy on some cases dying after bypass operations the lungs were extremely congested, with the alveoli filled with fibrin and red cells. Minor degrees of these changes may account for some post-operative infiltrations.

Tracheostomy was of great value in children and uncooperative adults. It permitted a sufficient bronchial toilet and the delivery of high concentrations of oxygen into the trachea. A 24-hour period of controlled respiration proved life-saving in a child with severe pulmonary oedema. Great care is necessary in using I.P.P. respiration in patients with severe pulmonary hypertension, as profound falls of cardiac output may result.

\section{Follow-up}

In the 28 survivors the defect remains clinically closed in 27. A small leak is still present in one case closed by suture. In one case pre-operative pulmonary hypertension has increased and in another pre-operative staphylococcal endocarditis has recurred intermittently. but appears cured. The cardiac rhythm has remained normal in all cases save one, in which there was a bout of ventricular tachycardia three months after operation. This reverted with procainamide and has not recurred.

\section{Summary}

Thirty-seven cases of uncomplicated ventricular septal defect have been repaired with the aid of the extracorporeal circulation at the Royal Prince Alfred Hospital since December, 1957.

There was a $24 \%$ mortality, the greater proportion of deaths occurring in the pulmonary hypertensive group.

Overall management and operative findings are outlined. Elective cardiac arrest was employed in 36, potassium citrate causing more frequent arrhythmias than intermittent aortic occlusion.

Twenty-one defects were sutured directly, 16 patched.

Post-operative features including heart-block, bleeding tendency, pulmonary complications, and infection are discussed.
In 27 of the 28 survivors the defect remains clinically closed.

Dr. V. J. McGovern was responsible for the pathological investigations and Dr. $\mathrm{H}$. Kronenberg for the haematological studies.

REFERENCES

Boyd, A. D., Tremblay, R. E., Spencer, F. C., and Bahnson, H. T. (1959). Ann. Surg., 150, 613.

Cooley, D. A., Belmonte, B. A., Latson, J. R., and Pierce, J. F. (1958). J.' thurac. Surg., 35, 131.

Gerbode, F., Braimbridge, M. V., and Melrose, D. G. (1958). Arch. Surg. (Chicago), 76, 82i.'

Kirklin, J. W., Harshbarger, H. G., Donald, D. E., and Edwards, J. E. (19577). J. thorac. Surg., 33. 45 .

- Patrick, R. T., and Theye. R. A. (1957b). Thorax, 12, 93. Melrose, D. G., Dreyer, B., Bentall, H. H., and Baker, J. B. E. (1955). Lancet, 2, 21

Perkins, H. A., Osborn, J. J., Hurt, R., and Gerbode, F. (1956). J. Lab. clin. Med., 48, 223.

Weirich, W. L., Gott, V. L., and Lillehei, C. W. (1958). Surg. Forum, 8, 360

\section{CONGENITAL TRICUSPID STENOSIS}

\section{A CASE TREATED BY OPEN OPERATION}

BY

W. E. MEDD, M.D., M.R.C.P.

AND

J. B. KINMONTH, M.S., F.R.C.S.

From the Cardiac Department and the Surgical Professorial Unit, St. Thomas's Hospital, London

Although tricuspid atresia (complete absence of a tricuspid valve orifice) is common, congenital tricuspid stenosis is less well recognized. This paper describes the clinical, laboratory, and operative findings in a child with congenital tricuspid stenosis and an atrial septal defect. Dilatation of the tricuspid orifice was performed with closure of the atrial septal defect, and great clinical improvement resulted. We have found no previous reference to the surgical treatment of congenital tricuspid stenosis.

\section{Case Report}

The patient, a girl aged 9, was referred to St. Thomas's Hospital by Dr. P. G. Todd. She had been cyanosed and short of breath since birth. In the first year of life she had been a slow feeder and was said to have become very blue and to have lost consciousness on two occasions. She did not walk until the age of 2 . but never squatted. On examination she was normally developed. There was central cyanosis and clubbing equal in the upper and lower halves of the body. The pulse was regular and the blood-pressure $105 / 80 \mathrm{~mm}$. Hg. There was an "a " wave of $2 \mathrm{~cm}$. visible in the jugular venous pulse. The apex beat was in the fourth left interspace just outside the mid-clavicular line, and its character suggested mild left ventricular hypertrophy. A systolic thrill and murmur were detected to the left of the lower end of the sternum. No diastolic murmur was heard. The second sound in the pulmonary area was finely split on inspiration, the later component not being accentuated.

A chest $x$-ray film (Fig. 1) showed diminished lung vascular markings but no cardiac enlargement. The electrocardiogram (Fig. 2) showed an rS pattern in V4R and V1 and an $R$ wave of $14 \mathrm{~mm}$. in V5. The $P$ wave in lead II was $2.5 \mathrm{~mm}$. Vectorial analysis showed a mean QRS axis of minus 15 degrees. The E.C.G. was regarded as within normal limits, but the position of the axis raised the possibility of left ventricular preponderance and the prominent $P$ waves right atrial hypertrophy. 
Cardiac catheterization, which had been performed three years previously, was repeated, and the findings at both procedures are shown in the Table. In summary the significant findings at the first catheterization were (1) evidence of a left-to-right shunt, first detected high in the right ventricle, and (2) a gradient across the tricuspid valve in diastole which measured $2 \mathrm{~mm}$. $\mathrm{Hg}$ at the start of diastole, $0.5 \mathrm{~mm}$. $\mathrm{Hg}$ just before the " $\mathrm{a}$ " wave, and an average of $2.75 \mathrm{~mm}$. $\mathrm{Hg}$ at the height of the " $\mathrm{a}$ " wave. Its significance is uncertain in view of its small size and the fact that the measurements were made from immediately consecutive rather than continuous withdrawal records. At the second catheterization the catheter passed into the aorta, and withdrawal records suggested it had passed through a ventricular septal defect, although on this occasion no evidence of a left-to-right shunt was found. The femoral artery saturation was $79 \%$. Right atrial pressure was raised, and a withdrawal tracing across the tricuspid valve showed no gradient at the start of diastole, a gradient of $5 \mathrm{~mm}$. just before the "a" wave, and of $3 \mathrm{~mm}$. at the height of the "a" wave.

At this stage it was concluded that there was a small ventricular septal defect, but that in view of low right ventricular pressure the cyanosis must be due to a right-toleft shunt elsewhere. An angiocardiogram was performed by Dr. J. Sutcliffe at the Hospital for Sick Children, Great Ormond Street, $25 \mathrm{ml}$. of $75 \%$ " urografin " being injected into the inferior vena cava. The dye entered the right atrium normally but early filling of the left atrium was also seen. This appearance (Figs. 3 and 4) was due to a column of dye passing along the atrial septum and entering the left atrium via a high atrial septal defect.

\section{Operation}

On March 19, 1959, a bilateral transverse thoracotomy incision was made in the bed of the fourth rib which gave good exposure. The right atrium was larger than normal and the right ventricle small. An abnormal coronary artery of considerable size ran across the infundibular region of the right ventricle (Fig. 5). The presence of this vessel was thought to make right ventriculotomy inadvisable.

There was a coarse systolic thrill over the right ventricle. A finger was inserted into the right atrium and an atrial septal defect about $1.5 \mathrm{~cm}$. in diameter was felt in the upper part of the septum. Marked tricuspid stenosis was present, the orifice admitting only the terminal interphalangeal joint. A systolic jet of blood could be felt by the tip of the finger in the right ventricle. and this was thought to indicate a small ventricular septal defect.
Under cardio-pulmonary by-pass the atrial septal defect was closed with continuous sutures reinforced with interrupted sutures. The tricuspid orifice was stretched with the finger untıl it would admit the proximal interphalangeal joint easily.

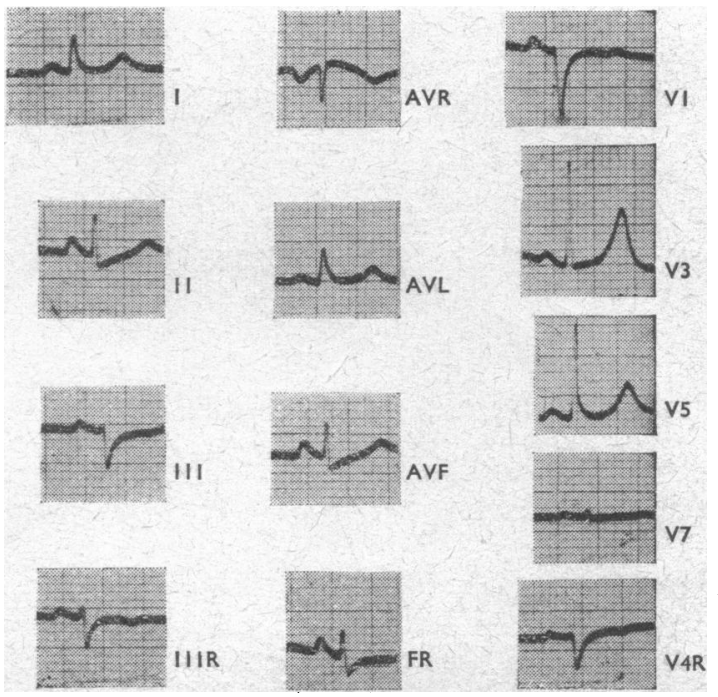

FIG. 2.-Electrocardiogram.

\begin{tabular}{|c|c|c|c|c|c|c|}
\hline \multicolumn{7}{|c|}{ Findings at Catheterization } \\
\hline \multirow{2}{*}{\multicolumn{3}{|c|}{ Site }} & \multicolumn{2}{|c|}{ Pressure (mm. Hg) } & \multirow{2}{*}{$\begin{array}{l}\mathbf{O}_{\mathbf{2}} \\
\text { (Vontent } \\
\text { (Vol. \%) }\end{array}$} & \multirow{2}{*}{$\underset{\text { Saturation }}{\mathbf{O}_{\mathbf{2}}}$} \\
\hline & & & Range & Mean & & \\
\hline $\begin{array}{l}\text { First catheteri } \\
\text { S.v.C. } \quad . \\
\text { R.A. . . } \\
\text { High R.v. } \\
\text { High R.v. } \\
\text { Low R.v. } \\
\text { P.A. .. }\end{array}$ & $\begin{array}{c}\text { on: } \\
\ldots \\
\ldots \\
\ldots \\
\ldots \\
\ldots\end{array}$ & $\begin{array}{l}\because \\
\therefore \\
\therefore \\
\because \\
\therefore\end{array}$ & $\begin{array}{c}4 \cdot \overline{5}-0 \\
20-0 \\
\overline{\overline{11-4}}\end{array}$ & $\begin{array}{l}\overline{2} \\
\frac{10}{7} \\
\overline{7}\end{array}$ & $\begin{array}{l}10.1 \\
10.7 \\
13.4 \\
12.7 \\
10.9 \\
12.8\end{array}$ & $\begin{array}{l}54.9 \\
58.2 \\
72.8 \\
69.2 \\
59.8 \\
69.9\end{array}$ \\
\hline $\begin{array}{l}\text { Second cathet } \\
\text { S.V.C. } \\
\text { High R.A. } \\
\text { Low R.A. } \\
\text { Mid R.v. } \\
\text { Low R.v. } \\
\text { M.P.A. .. } \\
\text { R.P.A. } \\
\text { Aorta } \\
\text { L.V. } \\
\text { F.A. }\end{array}$ & $\begin{array}{c}\text { ation } \\
\ldots \\
\ldots \\
\ldots \\
\ldots \\
\ldots \\
\ldots \\
\ldots\end{array}$ & $\begin{array}{l}. . \\
\because \\
\because \\
\because \\
\because \\
\because \\
\because \\
.\end{array}$ & $\begin{array}{l}\overline{7} \\
20-6 \\
41-4 \\
3 \overline{37-15} \\
\overline{98-70} \\
100-6 \\
112-80\end{array}$ & $\begin{array}{r}\overline{24} \\
\overline{82} \\
48 \\
100\end{array}$ & $\begin{array}{l}11.9 \\
13.4 \\
12.2 \\
11.5 \\
11.7 \\
12.7 \\
15.7 \\
15.5 \\
15.3\end{array}$ & $\begin{array}{l}61.4 \\
69.1 \\
62.4 \\
59.3 \\
60.3 \\
65.5 \\
65.5 \\
79.9 \\
78.9\end{array}$ \\
\hline
\end{tabular}

S.V.C. $=$ Superior vena cava. R.A. $=$ Right atrium. R.V. $=$ Right ventricle. P.A.=Pulmonary artery. M.P.A. = Main pulmonary artery. R.P.A. $=$ Right pulmonary artery. L.V. $=$ Left ventricle. F.A. $=$ Femoral artery.

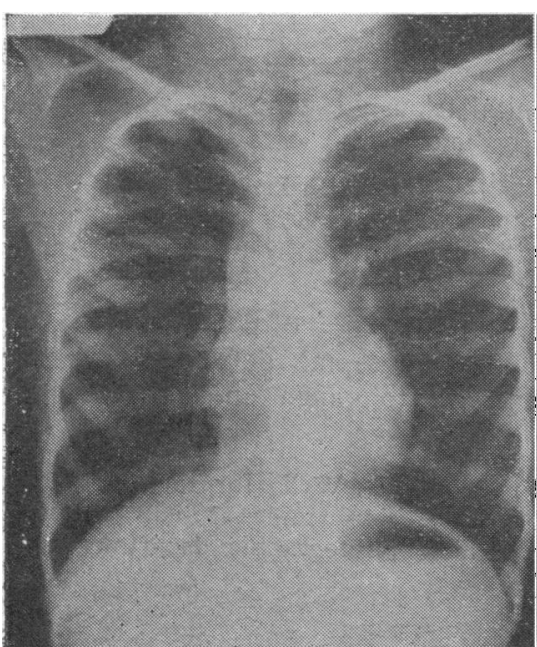

Fig. 1

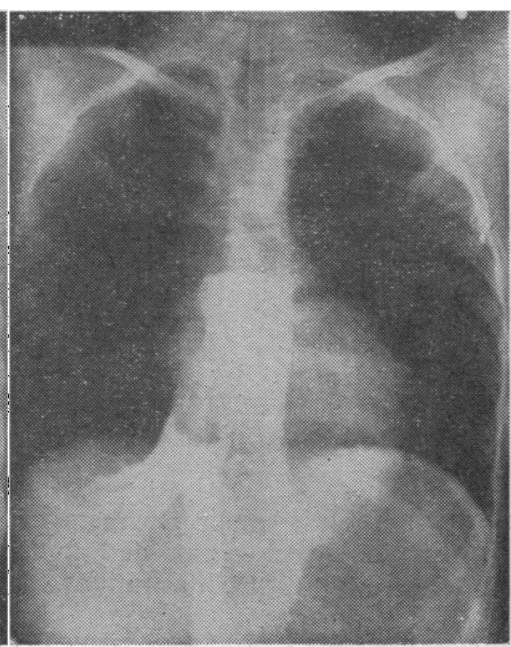

Frg. 3

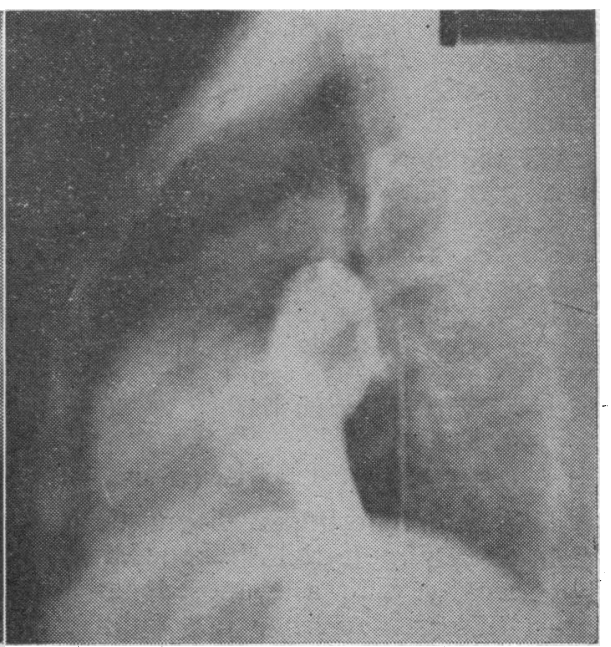

Fig. 4

Fig. 1.-Chest $x$-ray film (pre-operative). Fio. 3-Angiocardiogram with injection into inferior vena cava. Postero-anterior view showing early opacification of left atrium. Fio. 4.-Angiocardiogram. Left lateral view showing opacification of left atrium via high atrial septal defect. The right atrium and right ventricle are opacified anteriorly. 
There was no rise in pressure in the superior or inferior vena caval pressures when the normal circulation was re-established. The caval cannulae were therefore removed and the incision was closed. The post-operative period was uneventful.

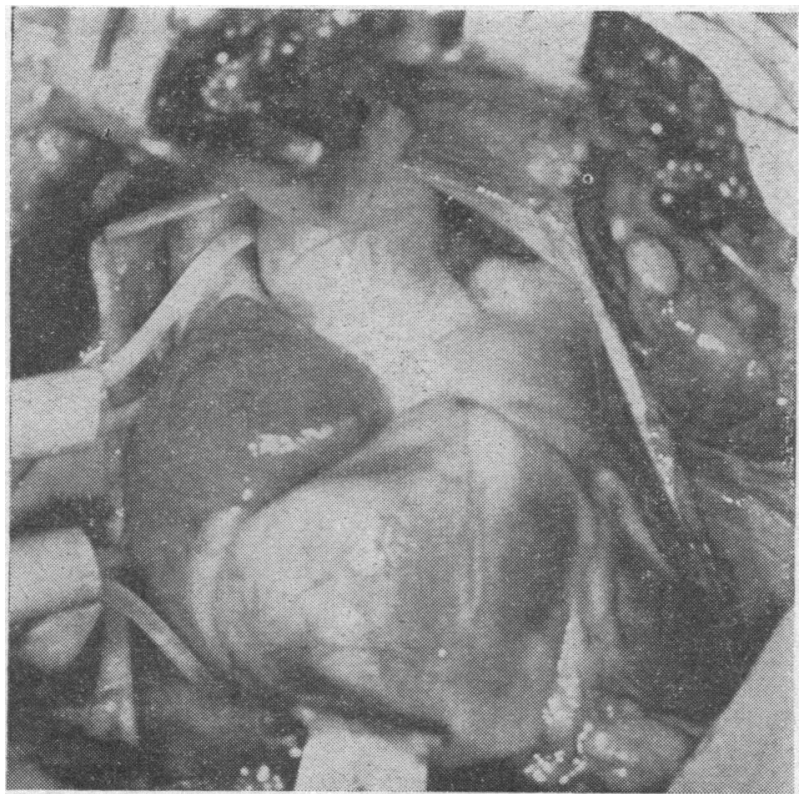

Fig. 5.-Heart at operation, showing large right atrium and small right ventricle with an abnormal coronary artery running across its infundibular portion.

\section{Post-operative Progress}

One month after operation the patient was much less cyanosed but the jugular venous pressure was raised $5 \mathrm{~cm}$. A to-and-fro murmur was heard in the pulmonary area; the significance of this was unknown. The systolic murmur of the ventricular defect was unchanged. The femoral arterial saturation was $\mathbf{8 8 . 2} \%$.

Six months after operation her mother stated that the girl had been much improved by it; her colour seemed normal and she ran about more and did not stop for rest or get out of breath. She was not cyanosed. There was an " a "wave of $2 \mathrm{~cm}$. in the jugular venous pulse. The pulmonary to-and-fro murmur was less loud. A year after operation her improvement was maintained. She had gained $10 \mathrm{lb}$. $(4.5 \mathrm{~kg}$.) in weight ; the venous pulse was normal ; and the auscultatory findings and the E.C.G. were unchanged. The chest $x$-ray film showed a bulge high on the left cardiac border. This had developed in the previous three months and was thought possibly to be a pericardial hernia.

The initial rise of venous pressure after operation may have been due to the small capacity of the right ventricle rather than residual tricuspid stenosis, since it fell to normal later. The slight cyanosis and arterial oxygen desaturation one month after operation was possibly pulmonary in origin, as six months after operation cyanosis was abolished. No further arterial sample was taken. The child was in good health when seen two years after operation, and there had been no further cyanosis.

\section{Discussion}

This case falls into a diagnostic group which has a right-to-left interatrial shunt without right ventricular hypertrophy. In a cyanosed patient with congenital heart disease evidence of right atrial hypertrophy without E.C.G. evidence of right ventricular hypertrophy suggests one of the following diagnoses: tricuspid atresia, Ebstein's malformation, pulmonary atresia with intact ventricular septum and small right ventricle, con- genital tricuspid stenosis, or isolated hypoplasia of the right ventricle and tricuspid valve (Medd, Neufeld, Weidman, and Edwards, 1961). We have also seen this combination in a girl thought to have pulmonary stenosis, right-to-left interatrial shunt, and corrected transposition of the great vessels. In corrected transposition the right ventricle lies relatively posteriorly and there may be no tall $R$ wave in V1 despite right ventricular hypertrophy.

In the present case tricuspid and pulmonary atresia were excluded by the passage of the catheter through both these orifices. Ebstein's malformation was thought unlikely in view of the absence of the typical heart contour on $x$-ray examination and any degree of right bundle-branch block on the E.C.G. The differentiation between congenital tricuspid stenosis and isolated hypoplasia of the right ventricle and tricuspid valve would appear theoretically to depend on the findings of a diastolic gradient across the tricuspid valve. In the present case the gradient varied between 0 and $5 \mathrm{~mm}$. $\mathrm{Hg}$ at various stages of diastole and was not noticed until the tracings were rescrutinized after operation. In other cases of congenital trieuspid stenosis no gradient at all has been found (Kjellberg, Mannheimer, Rudhe, and Jonsson, 1959), owing to the reduction in flow with an atrial septal defect shunting right to left. The differentiation of these two conditions must await further data.

We have found no previous account of operation on the valve in congenital tricuspid stenosis. In our patient this procedure combined with suture of the atrial septal defect produced great improvement. The possibility that the right ventricle may not be able to accommodate the increased flow must, however, be considered in future cases, and it may not always be advisable to close the atrial defect completely.

Although our patient had the typical murmur of a ventricular septal defect and the catheter was thought to have passed through it, a significant left-to-right shunt was detected only at one of the catheterizations. The methods in use at the time (a limited number of samples being estimated on the Haldane blood-gas apparatus) may well not detect small shunts, especially when the oxygen difference between left and right ventricular blood is reduced by a right-to-left interatrial shunt.

\section{Summary}

A case of congenital tricuspid stenosis with an atrial septal defect is described.

The differential diagnosis from other conditions causing cyanotic congenital heart disease with right atrial hypertrophy but without right ventricular hypertrophy is discussed.

The patient underwent dilatation of the tricuspid valve and closure of the atrial septal defect with great improvement in exercise tolerance and abolition of cyanosis.

We are grateful to Dr. W. D. Wylie for anaesthesia, to other members of our perfusion team for help with the surgery, and to the clinical photographic department for the illustrations.

\section{REFERENCES}

Kjellberg, S. R., Mannheimer, E., Rudhe, U., and Jonsson, B. (1959). Diagnosis of Congenital Heart Disease, p. 731. Year Book Publishers, Chicago

Medd, W. E., Neufeld, H. N., Weidman, W. H., and Edwards, J. E. (1961). Brit. Heart J., 23, 25. 